\title{
Parâmetros sedimentares e biogeoquímicos de mudanças do uso da terra em Alta Floresta (MT)
}

\author{
Alice Bosco-Santos ${ }^{1}$ \\ Gabriel Souza Martins ${ }^{2}$ \\ Renato Campello Cordeiro ${ }^{2 *}$ \\ Renato de Aragão Ribeiro Rodrigues ${ }^{3}$ \\ Marcela Conceição Guilles Cardoso ${ }^{2}$ \\ Bruno Turcq ${ }^{4}$ \\ José Carlos Sícoli Seoane ${ }^{5}$ \\ 'Departamento de Geologia e Recursos Naturais, \\ Instituto de Geociências, Universidade Estadual de \\ Campinas (UNICAMP) - Campinas (SP), Brasil. \\ ${ }^{2}$ Departamento de Geoquímica, Universidade \\ Federal Fluminense (UFF) - Niterói (RJ), Brasil. \\ ${ }^{3}$ Empresa Brasileira de Pesquisa \\ Agropecuária - Embrapa Agrosilvopastoral, \\ Sinop - Mato Grosso (MT), Brasil. \\ ${ }^{4}$ Institut de Recherche pour Développement \\ (IRD-LMTG-HYBAM) - Bondy, France. \\ ${ }^{5}$ Departamento de Geologia (IGEO), \\ Universidade Federal do Rio de Janeiro (UFRJ) - \\ Rio de Janeiro (RJ), Brasil.
}

*Autor correspondente: rcampello@yahoo.com

\section{Resumo}

O município de Alta Floresta, no norte do estado do Mato Grosso, Brasil, sofreu nos últimos 30 anos impactos relacionados à ocorrência de incêndios florestais em decorrência de mudanças no uso da terra. Este estudo objetivou avaliar mudanças ambientais e a ocorrência e dimensão de incêndios na região, utilizando parâmetros como a composição da matéria orgânica, granulometria e quantificação de partículas de carvão, depositadas num registro sedimentar de $80 \mathrm{~cm}$ de comprimento, em barragem artificial. Ao longo do testemunho SSW 150 , observou-se uma alteração brusca na composição granulométrica. De 80 a $19 \mathrm{~cm}$ de profundidade, o testemunho apresenta uma composição basicamente arenosa e a partir dessa profundidade, sua composição passa a ser argilo-siltosa. Tal característica sugere uma alteração na energia do ambiente deposicional a $19 \mathrm{~cm}$ de profundidade, interpretado como consequência da construção de uma rodovia próxima ao local de amostragem em meados dos anos 1990 e da predisponibilidade geomorfológica da região. A matéria orgânica ao longo do perfil corresponde a plantas $\mathrm{C} 3$, com valores $\delta^{13} \mathrm{C}$ extremamente negativos e razão $\mathrm{C} / \mathrm{N}$ de grande amplitude, indicando que a matéria orgânica tem a mesma origem. Altos valores de $\mathrm{C} / \mathrm{N}$ juntamente com a fração arenosa encontrada da base até $19 \mathrm{~cm}$ do testemunho caracterizam solo podzólico vermelho-amarelo associado a areias quartzosas álicas e hidromórficas. As condições geomorfológicas locais foram responsáveis pelo encharcamento do solo. Eventos intensos de queimadas estão registrados por partículas de carvão após $20 \mathrm{~cm}$ de profundidade, sugerindo queima de biomassa provocada pelos processos de mudança do uso da terra.

Palavras-chave: Alta Floresta, mudanças do uso da terra, queimadas.

\section{Abstract}

Alta Floresta, in the northern state of Mato Grosso, central Brazil, was profoundly impacted as a consequence of fires caused by intense land use changes over the past 30 years. The goal of this work was to study environmental changes and to correlate them with the occurrence and dimensions of fires in the region, using proxies that include the organic matter composition, particle size and quantification of charcoal particles deposited in the sedimentary record of $80 \mathrm{~cm}$ in artificial dam. The core SSW 150 shows a sharp change in the particle size parameter. Between 80 and $19 \mathrm{~cm}$, the SSW 150 record is basically compost of sand and, afterward, his composition is clay. These characteristic suggest a change in energy of the depositional environment at $19 \mathrm{~cm}$ due the construction of a highway near the site of collection in the 1990's and facilitated by the geomorphology of the area. The organic matter in the 
core corresponds to $\mathrm{C} 3$ plants, with extremely negative $\delta^{13} \mathrm{C}$ values and $\mathrm{C} / \mathrm{N}$ ratio of large amplitude, indicating that the organic matter in sediments have the same origin. High values of $\mathrm{C} / \mathrm{N}$ and the fraction of the size found on up to $19 \mathrm{~cm}$ depth of soil core characterized podzolic red yellow soil associated with quartz alics and hydromorphic sands. Geomorphologic conditions were responsible for the flooding of the soil due to excess water. Intense fire events are recorded in the core $S S W 150$ from $20 \mathrm{~cm}$ to the top associated to biomass burning by the processes of land change events.

Keywords: Alta Floresta, land change use, biomass burning.

\section{INTRODUÇÃO}

O desmatamento consiste em um dos maiores problemas ambientais dos países tropicais. No Brasil, o desmatamento é entendido como resultante de processos que envolvem o avanço da fronteira agropecuária, a expansão urbana desordenada, as redes de integração nacional, a exploração madeireira, além de condições climáticas naturais como períodos de seca (CETEM 2008). No relatório "Indicadores de desenvolvimento sustentável” (IBGE 2010), a Amazônia apresenta uma taxa contínua de desmatamento entre os anos de 1997 e 2004, quando atingiu seu máximo. A área desmatada no ano de 2009 representa um terço dos valores estimados para o ano de 2004.

A conversão de áreas de floresta nativa para produção agropecuária é a maior responsável pela emissão de carbono, em forma de $\mathrm{CO}_{2}$, para a atmosfera, no Brasil. As mudanças de uso do solo representam um enorme potencial de alteração dos processos que controlam a dinâmica de contaminantes no meio ambiente, de forma a alterar profundamente $o$ ecossistema e interferir no estoque de carbono local e global (Gullison et al. 2007).

Tendo em vista que as queimadas são processos críticos para os ecossistemas terrestres, pois acarretam consequências

\section{2. ÁREA DE ESTUDO}

Alta Floresta localiza-se ao extremo norte do estado do Mato Grosso, apresentando como coordenadas geográficas $55^{\circ} 30^{\prime}$ e $57^{\circ} 00^{\prime}$ longitude $\mathrm{O}$, e $9^{\circ} 00^{\prime} \mathrm{e} 11^{\circ} 00^{\prime}$ latitude S. O clima da região enquadra-se na categoria Am da classificação de Koopen (1948), úmido, com estação seca definida de junho a agosto. As temperaturas anuais variam entre $20^{\circ}$ e $30^{\circ} \mathrm{C}$, com média de $26^{\circ} \mathrm{C}$ (RADAMBrasil 1980), e precipitações médias anuais de $1.800 \mathrm{~mm}$ (INMET 2009). A vegetação característica é classificada como Floresta Ombrófila Densa (RADAMBrasil 1980). para a dinâmica da vegetação, para a química da atmosfera e para os ciclos biogeoquímicos (Whitlock et al. 2007), o dimensionamento da frequência e escala da ocorrência dos incêndios florestais na Amazônia é o primeiro passo para uma avaliação da potencialidade de transferência do carbono, proveniente da biomassa florestal, para a atmosfera, e de sua influência nas condições climáticas globais (Cordeiro 2000). Mudanças na dinâmica da floresta amazônica, principalmente guiadas por mudanças no uso da terra, têm o potencial de afetar a concentração atmosférica de $\mathrm{CO}_{2} \mathrm{e}$ interferir na razão de mudanças climáticas.

Considerando as alterações provocadas por mudanças no uso da terra, torna-se necessário o estudo de toda a dinâmica envolvida para dimensionar o impacto antrópico e identificar as alterações resultantes sobre o sistema natural. Portanto, esse trabalho objetivou identificar mudanças ambientais refletidas em um registro de barragem artificial referente a uma região de intensa mudança no uso da terra, em Alta Floresta, estado do Mato Grosso, e recriar o cenário ambiental, apontando a ocorrência e dimensão de eventos de queimada causados principalmente por interferências antrópicas e naturais no sistema.

Neste trabalho foram estudadas amostras de um testemunho de sondagem localizado a $150 \mathrm{~km}$ do centro do município, assentado sobre formações rochosas do Pré-Cambriano Superior, da formação Dardanelos caracterizados por arenitos claros a avermelhados, sobretudo arcoseanos, médios a grosseiros, mal selecionados (RADAMBrasil 1980). Esse município, assim como outros da região, tem colonização recente, iniciada nos anos de 1970, dependente de atividades baseadas na extração madeireira, agricultura e garimpo. Mais recentemente, se tornou pólo da atividade pecuária da região norte de Mato Grosso (Bernasconi et al. 2008). 


\section{MATERIAIS E MÉTODOS}

\subsection{Coleta e abertura do testemunho}

O testemunho sedimentar SSW 150 foi coletado no ponto de coordenadas $10^{\circ} 41^{\prime} 44.63^{\prime \prime} \mathrm{S}$ e $56^{\circ} 35^{\prime} 36.80^{\prime \prime} \mathrm{O}$, que dista aproximadamente $150 \mathrm{~km}$ da cidade de Alta Floresta (Figura 1). Esta barragem artificial foi formada pela construção de estrada não pavimentada, que formou um depósito sedimentar com resíduos de queima de biomassa vegetal.
A coleta foi realizada manualmente com tubo de alumínio de $7,5 \mathrm{~cm}$ de diâmetro e $81 \mathrm{~cm}$ de comprimento. O testemunho de $80 \mathrm{~cm}$ de comprimento foi aberto em campo com auxílio de uma serra elétrica, cortando-o longitudinalmente em duas metades. O testemunho foi seccionado de dois em dois centímetros respeitando-se as subdivisões litológicas.
Figura 1

Localização da área de estudo e ponto de coleta do testemunho SSW 150 no norte do estado de Mato Grosso.

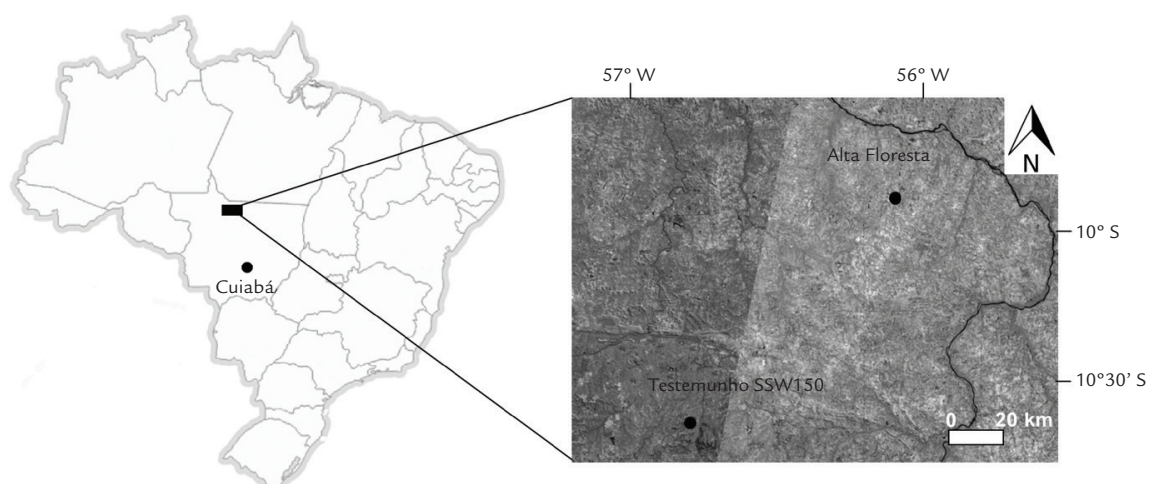

\subsection{Fracionamento granulométrico}

A análise de composição granulométrica foi realizada no laboratório de sedimentologia do Departamento de Geoquímica da Universidade Federal Fluminense. Para a realização desta análise, a matéria orgânica foi removida com peróxido de hidrogênio. Com o intuito de promover a dispersão do material, foi adicionada às amostras solução $0,5 \%$ de Na16P14O 43 por
$24 \mathrm{~h}$ e posteriormente, foi realizado tratamento com ultrassom por 5 minutos. A separação em faixas granulométricas foi realizada utilizando-se um analisador de partículas por difração a laser (CILAS 1064). Os dados foram tratados por meio do diagrama silte/areia/argila, do programa GRADISTAT, disponibilizado na Internet (http://www.kpal.co.uk/gradistat.html).

\subsection{Análise microscópica do material para identificação de carvões e estimativa do fluxo de carvão no registro sedimentar}

Uma alíquota de sedimento $(0,5 \mathrm{~g})$ foi atacada em solução alcalina $(\mathrm{NaOH}, 10 \%)$ para retirada da fração húmica. Após a completa extração do material húmico solúvel, a humina remanescente foi diluída em $50 \mathrm{~mL}$ de água e filtrada em filtros de acetato de celulose de $24 \mathrm{~mm}$ (HAWP, porosidade $0,45 \mu \mathrm{m}$ ) previamente secos e pesados. Os filtros foram secos, pesados e colados em lâminas de acrílico com acetato de etila. Nas lâminas, com área e massa do material analisado conhecido, foram determinadas as concentrações de partículas carbonizadas, bem como medidos a forma e tamanho das partículas, por meio de programa de análise de imagem da National Instruments acoplada a microscópio ótico de imagem refletida e transmitida (Leitz) com magnificação de 250 X, no Laboratório de Microscopia do Departamento de Geoquímica da Universidade Federal Fluminense.

O cálculo do fluxo de carvão no registro sedimentar foi realizado por intermédio do produto entre a taxa de sedimentação, a concentração (média) das partículas de carvão $\left(14,83 \times 10^{5}\right.$ part./g) e a densidade (média) do perfil sedimentar $\left(0,83 \mathrm{~g} / \mathrm{cm}^{3}\right)$. A taxa de sedimentação média foi estipulada supondo-se que o surgimento da estrada próximo ao local de coleta tenha ocorrido no ano de 1994, com base em imagens de satélite coletadas. O testemunho foi coletado no ano de 2005 correspondendo ao topo do perfil sedimentar.

\subsection{Determinação da composição elementar (carbono orgânico e nitrogênio total) e isotópica $\left(\delta^{13} \mathrm{C}\right.$ e $\left.\delta^{15} \mathrm{~N}\right)$ da matéria orgânica}

Para determinação desses parâmetros, as amostras foram descarbonatadas com solução de ácido clorídrico $0,5 \mathrm{~mol} / \mathrm{L}$. Os sedimentos descarbonatados foram analisados em sua composição elementar (carbono e nitrogênio) e isotópica $\left(\delta^{13} \mathrm{C}\right.$ e $\left.\delta^{15} \mathrm{~N}\right)$ utilizando um analisador elementar PDZ Europa
ANCA-GSL com interface para um espectrômetro de massa de razão isotópica PDZ Europa 20-20 no laboratório de isótopos estáveis da Universidade da Califórnia (Davis, EUA). As amostras foram queimadas a $1.020^{\circ} \mathrm{C} \mathrm{em}$ um reator com óxido de cromo e colbato de prata/óxido de cobalto. Após 
a combustão, os óxidos foram removidos usando um reator redutor (cobre reduzido a $650^{\circ} \mathrm{C}$ ), onde o carreador hélio flui através de uma armadilha de perclorato de magnésio, e uma armadilha opcional de $\mathrm{CO}_{2}$ é usada apenas para a análise de nitrogênio. Nitrogênio e $\mathrm{CO}_{2}$ são separados em uma coluna "Carbosieve GC" $\left(65^{\circ} \mathrm{C}, 65 \mathrm{~mL} / \mathrm{min}\right)$ antes de entrar no espectrômetro de massa de razão isotópica (Isotope Ratio Mass Spectrometer (IRMS)). Dois padrões de laboratórios foram analisados a cada 12 amostras. Foram usados padrões de laboratórios incluindo NIST 1547, NIST 1577b, acetanilida, celulose, glicina, sucrose e sulfato de amônia.
A composição isotópica $\left(\delta^{13} \mathrm{C}\right.$ e $\left.\delta^{15} \mathrm{~N}\right)$ é expressa em pormil e calculada por meio da razão entre o isótopo raro e o isótopo mais abundante $\left({ }^{13} \mathrm{C} /{ }^{12} \mathrm{C} \mathrm{e}{ }^{15} \mathrm{~N} /{ }^{14} \mathrm{~N}\right) \mathrm{em}$ relação a um padrão predeterminado. Para o carbono, o padrão utilizado é denominado Vienna PeeDee Belemnite (VPDB), e para o cálculo da composição isotópica do nitrogênio o padrão utilizado é o ar atmosférico, cujo $\delta^{15} \mathrm{~N}$ é igual a zero.

Os dados dos parâmetros citados acima (granulometria, partícular de carvão, carbono orgânico total (COT), nitrogênio total $(\mathrm{N}), \delta^{13} \mathrm{C}$ e $\left.\delta^{15} \mathrm{~N}\right)$ estão dispostos na Tabela.

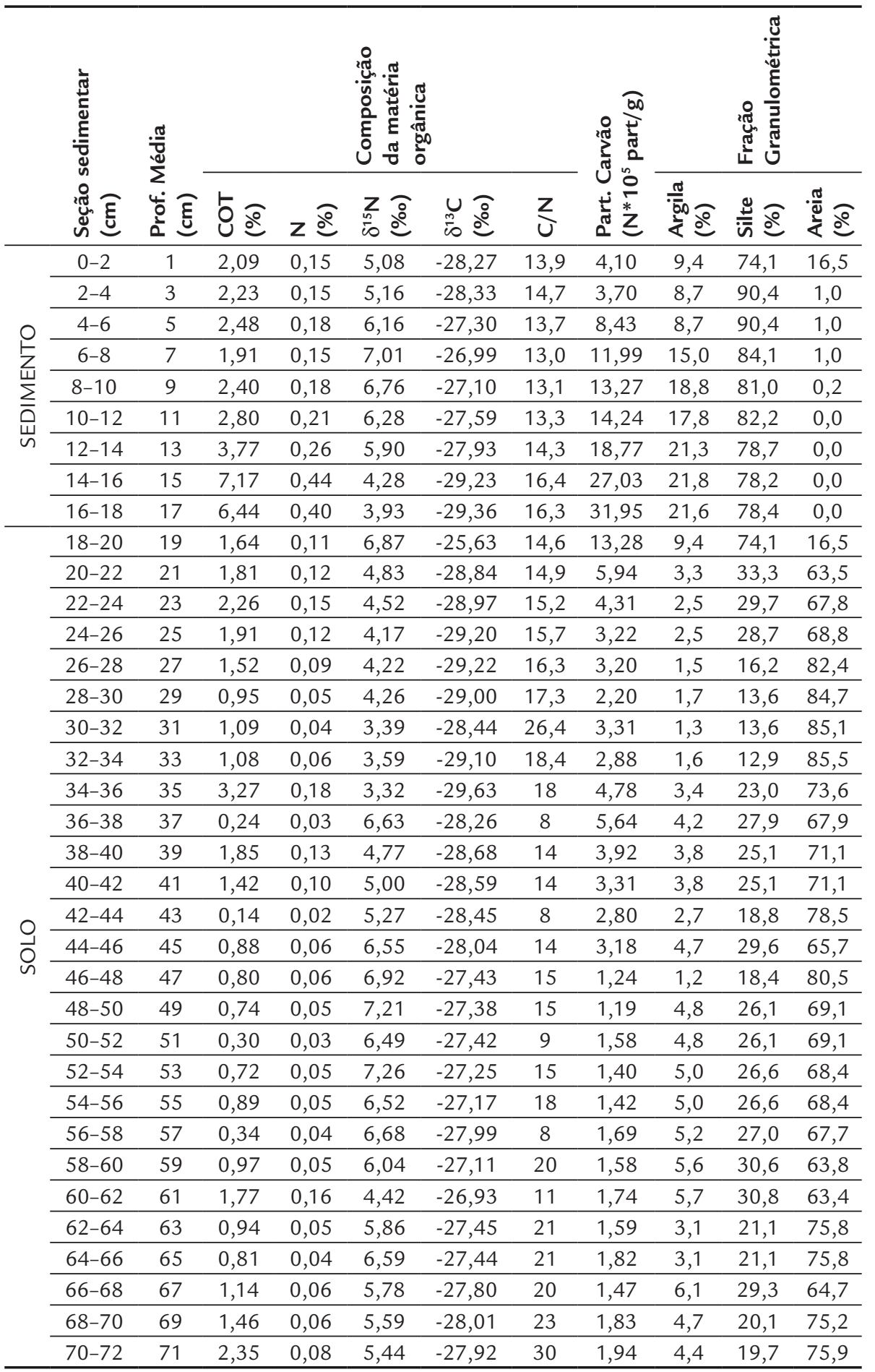

Tabela

Compilação dos resultados obtidos para o testemunho SSW 150- análise granulométrica, partículas de carvão e composição elementar e isotópica da matéria orgânica. 


\begin{tabular}{|c|c|c|c|c|c|c|c|c|c|c|c|c|}
\hline \multirow[b]{4}{*}{ Tabela } & \multirow{5}{*}{$\begin{array}{l}0 \\
0 \\
\sim\end{array}$} & $72-74$ & 73 & 1,93 & 0,08 & 4,36 & $-28,39$ & 25 & 1,50 & 4,8 & 28,2 & 67,0 \\
\hline & & $74-76$ & 75 & 2,57 & 0,09 & 4,24 & $-28,50$ & 27 & 2,25 & 4,1 & 24,4 & 71,5 \\
\hline & & $76-48$ & 77 & 3,63 & 0,12 & 3,96 & $-28,83$ & 31 & 2,22 & 4,5 & 25,6 & 69,9 \\
\hline & & $78-80$ & 79 & 1,07 & 0,06 & 4,83 & $-27,30$ & 19 & 1,32 & 4,2 & 23,7 & 72,1 \\
\hline Continuacão & & $80-82$ & 81 & 3,73 & 0,12 & 3,24 & $-29,05$ & 32 & 2,60 & 3,9 & 21,8 & 74,2 \\
\hline
\end{tabular}

\section{RESULTADOS}

\subsection{Granulometria}

O perfil granulométrico do testemunho está representado na Figura 2. O testemunho SSW 150 apresentou da base ( $80 \mathrm{~cm}$ de profundidade) até $19 \mathrm{~cm}$ de profundidade altos teores de areia, com uma composição maior que $80 \%$ em comparação às frações silte e argila, mantendo uma distribuição praticamente constante ao longo desse intervalo. A partir de $19 \mathrm{~cm}$, houve uma queda abrupta de areia, com consequente desaparecimento dessa classe de grão, e aumento de silte e argila. A areia fina é a maior porção constituinte da base do testemunho $(80 \mathrm{~cm})$ até $19 \mathrm{~cm}$ de profundidade, sugerindo um ambiente lótico, ou seja, um ambiente de maior hidrodinâmica. A fração silte está presente ao longo de todo o perfil sedimentar, constituindo em média 38\% do total. As frações silte e argila, juntas, representam, em média, 97,8\% do perfil granulométrico de $19 \mathrm{~cm}$ até o topo do testemunho.

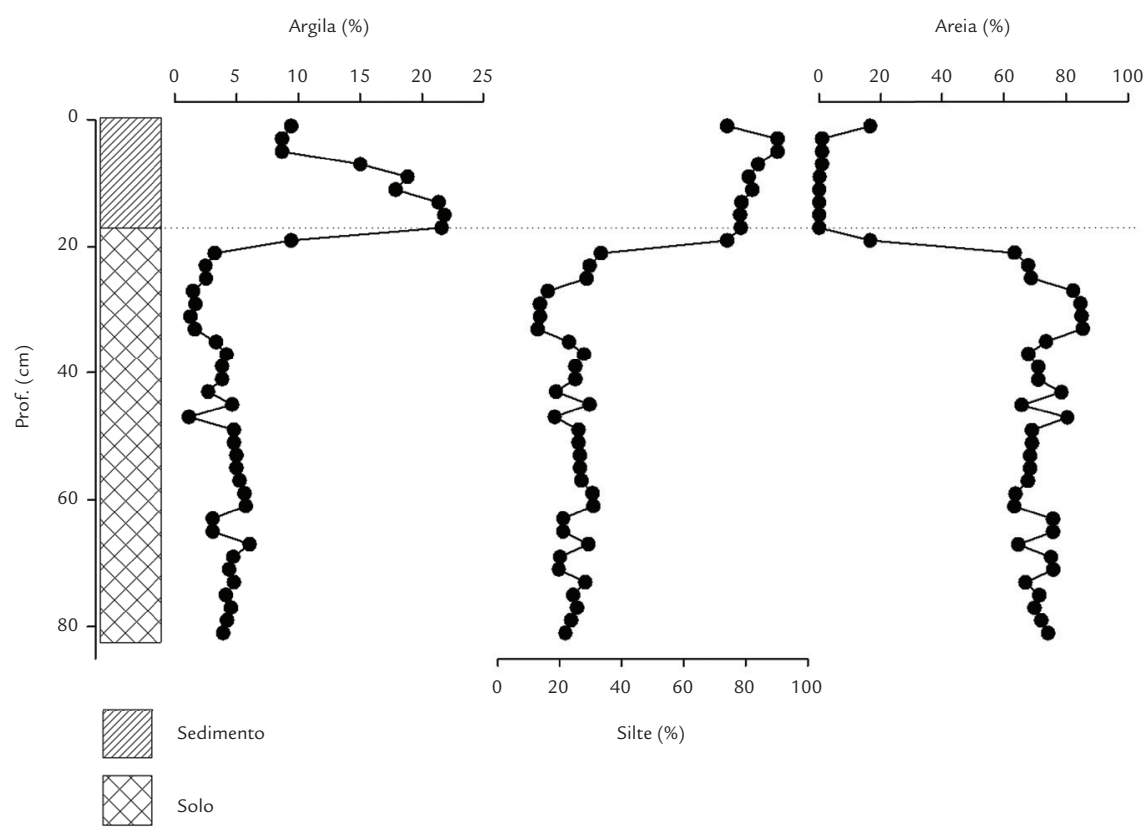

\subsection{Carbono orgânico e nitrogênio orgânico total}

A quantidade de matéria orgânica presente no sedimento pode ser estimada pelos valores percentuais de carbono orgânico total, uma vez que este representa $50 \%$ de sua constituição. O perfil de carbono orgânico total está representado na Figura 3. Ao longo do perfil, a porcentagem de carbono apresenta valor máximo de $7,16 \%$ a $15 \mathrm{~cm}$ de profundidade e mínimo de $0,14 \%$ a $43 \mathrm{~cm}$. De forma geral, observa-se no perfil teores de carbono sem alterações bruscas até a profundidade de $19 \mathrm{~cm}$, onde se inicia, em direção ao topo do perfil, um grande pico de concentração do elemento (Figura 3).

Os valores encontrados para nitrogênio apresentam um padrão muito similar àquele encontrado para o carbono orgânico total, com máximo de $0,43 \%$ a
$15 \mathrm{~cm}$ de profundidade e mínimo de $0,01 \%$ a $43 \mathrm{~cm}$. As concentrações de nitrogênio estão representados na Figura 3.

A razão entre carbono e nitrogênio orgânico total pode ser utilizada para distinguir matéria orgânica de origem algal daquela originária de plantas vasculares (Meyers 1994, 1997, 2003). Os valores de C/N obtidos neste trabalho são de grande amplitude (Figura 3), variando de 26 a $31 \mathrm{~cm}$ de profundidade a 8 a $46 \mathrm{~cm}$. A variabilidade dessa relação denota mudanças do ambiente deposicional provavelmente associado a flutuações nos regimes de inundação do ambiente, onde menores relações $\mathrm{C} / \mathrm{N}$ denotam um maior regime de inundação com adição de matéria orgânica de origem fitoplanctônica. 

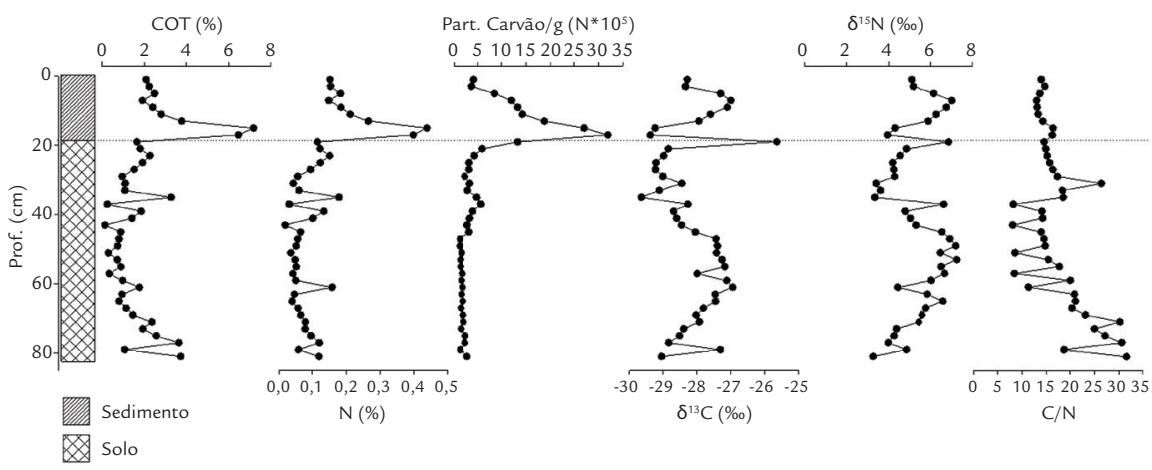

Figura 3

Resultados da composição de carbono orgânico total e nitrogênio total $(\mathrm{N})$, concentração de partículas de carvão, composição isotópica ( $\delta^{13} \mathrm{C}$ e $\delta^{15} \mathrm{~N}$ ) e razão $\mathrm{C} / \mathrm{N}$ do testemunho SSW 150.

\subsection{Isótopos estáveis de carbono $\left(\delta^{13} C\right)$ e nitrogênio $\left(\delta^{15} N\right)$}

Os valores de $\delta^{13} \mathrm{C}$ e $\delta^{15} \mathrm{~N}$ estão representados na Figura 3. Os valores de $\delta^{13} \mathrm{C}$ encontrados oscilam entre o máximo valor de $-25,6 \%$ a $19 \mathrm{~cm}$ de profundidade e o mínimo valor de $-29,6 \%$ a $35 \mathrm{~cm}$, A essa profundidade ocorre a alteração da energia deposicional refletida na granulometria e nos máximos de $\delta^{15} \mathrm{~N}, \delta^{13} \mathrm{C}$, NT e partículas de carvão (Figura 3).

Os valores de $\delta^{15} \mathrm{~N}$ apresentam padrão de variação ao longo do perfil semelhante aos valores de $\delta^{13} \mathrm{C}$ com valor máximo de $7,25 \%$ a $53 \mathrm{~cm}$ de profundidade e mínimo de $3,32 \%$ a $35 \mathrm{~cm}$. Apesar de não representar o maior valor de $\delta^{15} \mathrm{~N}$, a $19 \mathrm{~cm}$ de profundidade, também é observado um alto valor $\left(6,86 \%\right.$ ) de $\delta^{15} \mathrm{~N}$, corroborando a hipótese de que algum fator tenha alterado o ambiente de forma que essa perturbação ficou evidenciada no perfil sedimentar entre 19 e $15 \mathrm{~cm}$.

\subsection{Análise microscópica das partículas de carvão e estimativa do fluxo de carvão no registro sedimentar}

O número de partículas de carvão, representado na Figura 3, se mantém praticamente constante da base do perfil até a profundidade de $17 \mathrm{~cm}$, quando chega a um máximo $32 \times 10^{5}$ partículas de carvão/grama de sedimento. Após esse marco, os valores tendem a diminuir até o topo do testemunho. Cabe ressaltar que o pico na quantidade de partículas de carvão, presente no perfil sedimentar, ocorre na mesma profundidade das bruscas alterações na granulometria, COT, $\mathrm{N}, \delta^{15} \mathrm{~N}$ e $\delta^{13} \mathrm{C}$. Tal característica sugere uma correlação entre o aumento na frequência e magnitude da queima de biomassa com as abrutas modificações na composição da matéria orgânica.

Considerando-se o ano de 1994 como o ano de construção da estrada responsável pela alteração na energia do ambiente deposicional (marcado a partir da profundidade de $18 \mathrm{~cm}$ ) e sabendo-se que o topo do perfil corresponde ao ano de 2005 (ano de coleta do testemunho), a taxa de sedimentação média para o testemunho SSW 150 é de:

Taxa de sedimentação $=18 \mathrm{~cm} /(2005-1994)$ anos $=$ $18 \mathrm{~cm} / 11$ anos $=1,64 \mathrm{~cm} /$ ano

O cálculo do fluxo médio de carvão no perfil sedimentar, que corresponde ao produto entre a taxa de sedimentação, a concentração (média) das partículas de carvão $\left(14,83 \times 10^{5}\right.$ part./g) e a densidade (média) do perfil sedimentar $\left(0,83 \mathrm{~g} / \mathrm{cm}^{3}\right)$ resulta em $2,01 \times 10^{6}$ part $\mathrm{cm}^{2} /$ ano.

\section{DISCUSSÃO}

Os dados das frações granulométricas, razão C/N e número de partículas de carvão ao longo do perfil sedimentar estudado sugerem que a energia do ambiente deposicional foi alterada próxima a $19 \mathrm{~cm}$ de profundidade. Atividades antrópicas, como a construção da estrada responsável pela criação da barragem artificial onde a coleta do testemunho foi realizada, poderiam explicar essa transformação. A flo-

resta densa, observada pela imagem de satélite, dificulta a visualização da estrada adjacente ao testemunho SSW-150. Observa-se na imagem de 1990 da Figura 4, que não havia estrada próxima ao local do testemunho aqui estudado. Numa imagem de 1994 (Figura 4), pode ser observado o traçado da estrada pela floresta, bem como um princípio de desmatamento. 
Figura 4

Composição colorida Landsat Sensores TM (resolução espacial 30 metros) para a área de coleta do testemunho SSW 150.
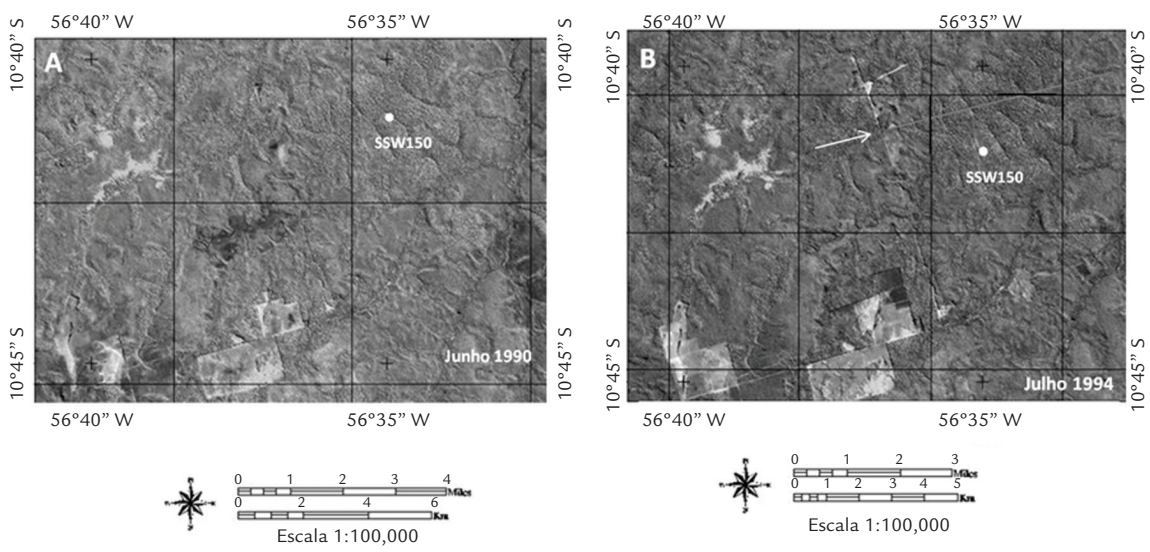

Da base do testemunho até a profundidade de $19 \mathrm{~cm}$, partículas grossas foram depositadas (areia média, areia fina, areia superfina e silte supergrosso), caracterizando um ambiente de alta energia. A partir de $19 \mathrm{~cm}$ de profundidade correspondente ao ano de 1994, aproximadamente, verifica-se uma mudança abrupta na distribuição das frações granulométricas. A partir dessa profundidade, a granulometria se torna fina (silte grosso, silte médio, silte fino, silte superfino e argila), característica de ambiente de baixa energia. Esse aporte de sedimentos de granulometria mais fina a este ambiente deposicional pode ser resultante da construção da estrada, em um interflúvio topograficamente mais elevado em relação às drenagens laterais. A estrada passou a funcionar como área-fonte de sedimentos durante episódios de chuvas, fato agravado pelo tráfego de veículos, que juntos respondem pela erosão dos sedimentos dessas áreas mais elevadas para aquelas de topografia mais baixa. As alterações no comportamento esperado para a distribuição granulométrica dos $19 \mathrm{~cm}$ superficiais do testemunho sugerem modificações e alterações no escoamento superficial, propiciando a estagnação e o acúmulo de água no local.

Sustentando a teoria de que as modificações granulométricas são resultantes de atividade humana, valores altos de $\mathrm{C} / \mathrm{N}$ próximos à base do testemunho sugerem que o ambiente era constituído de solo. Amostras de solo analisadas próximo à área de estudo apresentaram C/N variando de 10 a 29, muitas vezes aumentando com a profundidade (RADAMBrasil 1980). Dados gerados pelo RADAMBrasil (1980) em área muito próxima ao ponto de coleta do testemunho, descrita como associação de solos areias quartzozas álicas e podzólico vermelho - amarelo e areias quartzosas hidromórficas, também apontaram grande amplitude nos valores de $\mathrm{C} / \mathrm{N}$ (de 10 a 18), e predominância, e predominância de areia nas amostras estudadas.

Ao assumir que se trata de um testemunho que registra modificações na energia do ambiente, com a formação de um ambiente lêntico, pode-se verificar que até a profundidade onde ocorreu essa alteração, a granulometria, altos valores de $\mathrm{C} / \mathrm{N}$ e a geomorfologia da região suportam e indicam ambiente com solo encharcado. Entretanto, ainda admitindo-se essa transformação para um ambiente lêntico, o esperado seria uma redução dos valores de $\mathrm{C} / \mathrm{N}$ em decorrência do aumento de produtividade gerado pela presença de vegetação fitoplanctônica, no caso, algas lacustres. No entanto, os valores de $\mathrm{C} / \mathrm{N}$ entre $19 \mathrm{~cm}$ de profundidade e o topo do perfil não diminuem, apontando para vegetação do tipo C3. $\mathrm{O}$ diagrama $\delta^{13} \mathrm{C} \times \mathrm{C} / \mathrm{N}$ (Figura 5) sugere predominância de plantas terrestres e do tipo $\mathrm{C} 3$ em todo o perfil sedimentar $\left(\delta^{13} \mathrm{C}\right.$ varia de -23 a $-36 \%$ e $\left.\mathrm{C} / \mathrm{N}>20\right)$. Os valores de $\delta^{13} \mathrm{C}$ apresentam pouca variação ( - 30 a $-26 \%$ ) ao longo do perfil, com valores que indicam predominância de vegetação $\mathrm{C} 3$ ou de algas lacustres. No entanto, o fitoplâncton apresenta valores da relação $\mathrm{C} / \mathrm{N}$ entre 4 e 10 , inferiores àqueles encontrados para vegetação do tipo C3 (Meyers 1994, 1997, 2003). Apenas quatro amostras obtiveram razão $\mathrm{C} / \mathrm{N}$ correspondente a influência de vegetação fitoplanctônica $(37 \mathrm{~cm}, 43 \mathrm{~cm}, 51 \mathrm{~cm}$ e $57 \mathrm{~cm}$ de profundidade). As amostras correspondentes às profundidades de $29 \mathrm{~cm}$ ao topo apresentaram valores de $\delta^{13} \mathrm{C}$ com baixa variação $(\sim-17$ a $-13 \%$ o), e a razão $\mathrm{C} / \mathrm{N}$ se torna constante como consequência da criação do ambiente lêntico.

É possível que a origem da vegetação não tenha mudado apesar da formação de uma barragem artificial, pois pode se tratar de uma área não favorável à proliferação de algas em razão da ausência de luz, nutrientes ou pH desfavorável. Nesse caso, a relação $\mathrm{C} / \mathrm{N}$ estaria refletindo o aporte de material que é depositado na área como consequência de escoamento superficial da área no entorno.

A razão $\mathrm{C} / \mathrm{N}$ pode ter sido modificada como consequência de outro processo. Um aumento na proporção de nitrogênio pode ser verificado entre $19 \mathrm{~cm}$ de profundidade e o topo, onde se assumiu a formação do ambiente de baixa energia. No entanto, um aumento substancial da porcentagem de carbono orgânico, que não é reflexo da origem da vegetação, pode ter influenciado a relação $\mathrm{C} / \mathrm{N}$ de forma que torna visível o aumento substancial de nitrogênio no ambiente, este sim reflexo da vegetação, já que os dois elementos apresentam concentrações mais altas na mesma profundidade $(15 \mathrm{~cm})$, praticamente não alterando a relação C/N. Cordeiro et al. (2008b) correlacionaram um aumento da porcentagem de carbono na matéria orgânica com um aumento do número de partículas de carvão no testemunho CSN 93/3 na serra de Carajás, estado do Pará. Essa relação parece ter ocorrido no testemunho estudado como sugerido na Figura 3.

O aumento substancial de partículas de carvão no testemunho SSW 150, com pico a $17 \mathrm{~cm}$ de profundidade, pode ser correlacionado diretamente a atividades antrópicas de 


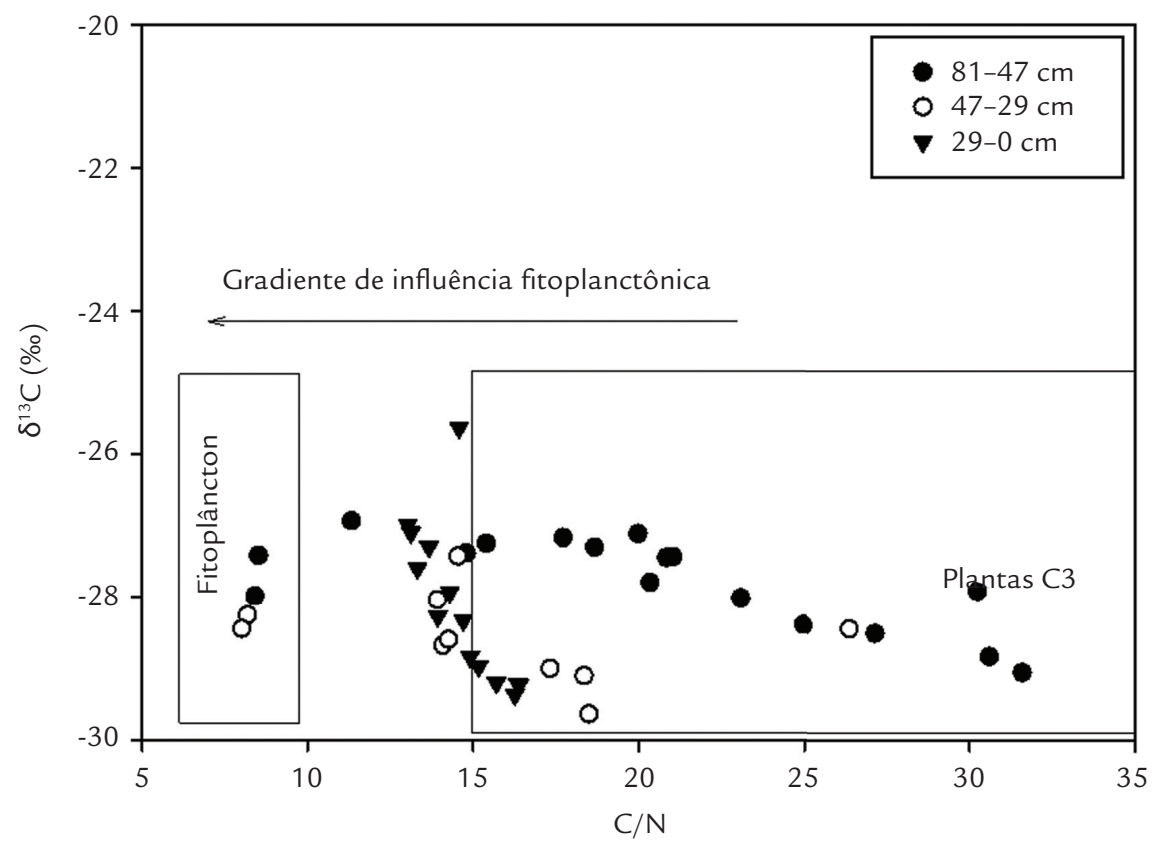

Figura 5

Diagrama $\delta^{13} \mathrm{C} \times \mathrm{C} / \mathrm{N}$ referente aos três intervalos: primeira fase (círculos pretos) 81 a $47 \mathrm{~cm}$ de profundidade; segunda fase (círculos brancos) - 47 a $19 \mathrm{~cm}$ de profundidade; e terceira fase (triângulos) - $19 \mathrm{~cm}$ de profundidade ao topo (intervalos de valores estipulados em Meyers 1994). queima de biomassa. As partículas de carvão presentes no testemunho estão concentradas após $19 \mathrm{~cm}$ em direção ao topo, coincidindo com a profundidade que hipoteticamente representa o impacto da abertura da estrada, por meio de corte e queima de vegetação densa. Além disso, na região Amazônica, e especificadamente no município de Alta Floresta em Mato Grosso, segundo Michalski et al. (2008), existe uma correlação positiva entre a distância das estradas e áreas desmatadas, visto que elas são responsáveis pelo acesso de empresas de exploração madeireira e de outras perturbações antrópicas, como a criação de áreas de pasto, a florestas remanescentes. Essa mesma correlação entre estradas e desmatamento foi abordada por Kirby et al. (2006), os quais afirmaram que estradas pavimentadas impactam mais do que aquelas sem pavimentação, pois incentivam atividades como a agricultura próximas a ela.

$\mathrm{O}$ estudo do testemunho permite supor dois fenômenos em sequência representados aproximadamente nos últimos $20 \mathrm{~cm}$ do registro estratigráfico: a construção da estrada que levou à desorganização da drenagem natural com a criação de alagamentos, o que caracteriza baixo nível de energia hidrodinâmica; e os subsequentes incêndios provenientes da alteração do uso da terra em locais próximos, que acarretaram a sedimentação de carvão.

O fluxo de carvão de $2,01 \times 10^{6}$ part. $\mathrm{cm}^{2} /$ ano registrado da profundidade de $19 \mathrm{~cm}$ ao topo do testemunho SSW 150 é superior aos fluxos reportados entre os anos de 1978 e $1985\left(2,6 \times 10^{5}\right.$ part. $\left.\mathrm{cm}^{2} / \mathrm{ano}\right)$ e entre 1992 e 1996 $\left(7,6 \times 10^{5}\right.$ part. $\left.\mathrm{cm}^{2} / \mathrm{ano}\right)$ para outro testemunho coletado anteriormente na região de Alta Floresta (Cordeiro et al. 2002). Portanto, o fluxo de partículas de carvão, na região, aumentou aproximadamente uma ordem de grandeza nos últimos 27 anos (de 1978 até 2005), como consequência das atividades antrópicas ligadas a mudanças no uso da terra. O fluxo encontrado neste trabalho também é superior ao fluxo médio encontrado no trabalho de Cordeiro et al. (2008b) em testemunho coletado na região de Carajás $\left(4,2 \times 10^{4}\right.$ part. $\left.\mathrm{cm}^{2} / \mathrm{ano}\right)$, região leste amazônica, área conhecidamente atingida por eventos de queimada conforme a literatura. A título de comparação, o fluxo de partículas de carvão registrado na Lagoa da Pata, localizada no morro dos seis lagos (extremo norte do estado da Amazonas), há aproximadamente 47.000 anos cal AP, foi de $12 \times 10^{3}$ part. $\mathrm{cm}^{2} /$ ano e representa um fluxo natural, sem influência antrópica (Cordeiro et al. 2011).

Picos de carvão no sedimento são registros de queima de biomassa. Muitas vezes, o número de partículas de carvão encontradas no sedimento pode ser relacionado à magnitude da vegetação arbórea presente que foi queimada e à intensidade dos eventos de incêndio (Pessenda et al. 2004). A constituição química do carvão é predominantemente de carbono, tornando-se, portanto, uma espécie de "sequestrador" do elemento e uma medida direta do potencial de carbono liberado para a atmosfera pela combustão da biomassa (Carcaillet et al. 2002).

$\mathrm{O}$ aumento na quantidade e magnitude da queima de biomassa é evidente próximo a $20 \mathrm{~cm}$ de profundidade, em decorrência do aumento de partículas de carvão no registro

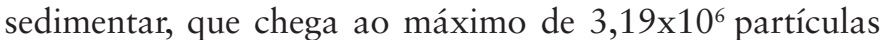
de carvão/grama de sedimento a $17 \mathrm{~cm}$ de profundidade. Esses eventos de incêndio com magnitude amplificada após a construção da estrada, devem estar associados a atividades antrópicas de transformação do uso da terra, logo depois de criado o acesso a áreas antes intocadas. O pico de acúmulo de partículas de carvão a $17 \mathrm{~cm}$ de profundidade parece se refletir na percentagem de carbono encontrado na matéria orgânica, que atinge um pico a $15 \mathrm{~cm}$ de profundidade. Nessa mesma profundidade, ocorre um pico na concentração de nitrogênio, que também pode estar associado à deposição de elementos nitrogenados liberados pelos eventos de queimada, caso não seja reflexo de constituição algal da matéria orgânica. 
O desmatamento por si só produz grandes quantidades de resíduos de biomassa cortada ou queimada. Esses resíduos, como folhas, madeiras e raízes, que são esquecidas após o desmate, são escoados para depósitos sedimentares pela água da chuva. A lavagem de um terreno recém-des-

\section{CONCLUSÃO}

O registro sedimentar do testemunho SSW 150 apresenta uma alteração na energia do ambiente deposicional, marcada a $19 \mathrm{~cm}$ de profundidade. A construção de uma rodovia próxima ao local de coleta em meados dos anos 1990, juntamente a uma predisponibilidade geomorfológica da área em questão, levou à criação de um ambiente de água parada e granulometria fina, de baixa energia, lêntico, característico de uma barragem artificial.

A origem da matéria orgânica não foi alterada substancialmente de forma que em todo o perfil a vegetação corresponde a plantas C3, como demonstrado pelos valores de $\delta^{13} \mathrm{C}$ muito negativos e razão $\mathrm{C} / \mathrm{N}$ de grande amplitude. Entretanto, variabilidades são observadas denotando mudanças no regime hidrológico do ambiente estudado.

\section{AGRADECIMENTOS}

Os autores agradecem ao CNPq pelo investimento fornecido ao projeto por meio do Processo 482837/2009-8, Edital MCT/CNPq 14/2009 - Universal - Faixa C - "Interconexões entre mudanças paleoclimáticas, o sistema de monção sul-americana e distúrbios relacionados ao fogo em sistemas florestais", matado, rico em matéria orgânica, também deve explicar os picos percentuais de carbono e nitrogênio a $15 \mathrm{~cm}$ de profundidade após o período de queimadas evidenciado pelo aumento das partículas de carvão a $19 \mathrm{~cm}$ de profundidade (Figura 3).

Eventos de queimadas estão registrados no testemunho SSW 150 de $20 \mathrm{~cm}$ de profundidade ao topo do perfil, sugeridos pelo aumento do número de partículas de carvão, que atinge um pico a $17 \mathrm{~cm}$ de profundidade. $\mathrm{O}$ pico de concentração de carbono e de nitrogênio observado a $15 \mathrm{~cm}$ de profundidade pode estar diretamente relacionado com a deposição de carvão e resíduos de combustão, provenientes de emissões de um período de queimada.

De acordo com os dados obtidos, pode-se inferir que processos de mudanças no uso da terra, como a construção de uma rodovia, podem impactar e modificar o ambiente natural. Isso favorece, por exemplo, a intensificação de queimadas no entorno da região, o que facilita o acesso a áreas florestais remanescentes, levando a modificações no ambiente natural. Assim, conclui-se que processos de mudanças no uso da terra afetam substancialmente o equilíbrio da biota terrestre.

CNPq Processo 312829/2009-4 - Produtividade em Pesquisa PQ-2009 - "Dinâmica do ciclo carbono na Amazônia durante o Holoceno" e as bolsas dos alunos envolvidos. O estudo também faz parte da cooperação internacional CNPq - IRD (Institut de Recherche pour le Développement).

\section{REFERÊNCIAS}

Bernasconi P., Abad R., Micol L. 2008. Diagnóstico ambiental do município de Alta Floresta - MT.

Carcaillet C., Almquist H., Asnong H., Bradshaw R.H.W., Carrión J.S., Gaillard M.J., Gajewski K., Haas J.N., Haberle S.G., Hadorn P., Müller S.D., Richard P.J.H., Richoz I., Rösch M., Sánchez Goñi M.F., von Stedingk H., Stevenson A.C., Talon B., Tardy C., Tinner W., Tryterud E., Wick L., Willis K.J. 2002. Holocene Biomass Burning and Global Dynamics of the Carbon Cycle. Chemosphere, 49:845-863.

CETEM - CENTRO DE TECNOLOGIA MINERAL. 2008. Ecorregião XinguTapajós - a evolução do desmatamento no município de Alta Floresta, MT (1970-200).

Cordeiro R.C. 2000. Ocorrência de incêndios e mudanças paleoambientais de ecossistemas amazônicos em diversas escalas temporais. Tese de Doutorado, Departamento de Geoquímica, Universidade Federal Fluminense, 236 p.

Cordeiro R.C., Turcq, B., Ribeiro M.G., Lacerda L.D., Capitâneo J., Oliveira da Silva A., Sifeddine A., Turcq P.M. 2002. Forest fire indicators and Mercury deposition in na intense land use change region in the Brazilian Amazon (Alta Floresta, MT). The Science of the Total Environment, 293:247-256.

Cordeiro R.C., Moreira-Turcq P.F., Turcq B.J., Moreira L.S., Rodrigues R.C., Lima da Costa R.L., Sifeddine A., Simões-Filho F.F.L. 2008a. Acumulação de Carbono em Lagos Amazônicos como Indicador de Eventos Paleoclimáticos e Antrópicos. Oecologia Brasiliensis, 12:130-154. 
Cordeiro R.C., Turcq B., Suguio K., Silva A.O., Sifeddine A., Volkmer-Ribeiro C. 2008b. Holocene fires in East Amazonia (Carajás), new evidences, chronology and relation with paleoclimate. Global and Planetary Change, 61:49-62.

Cordeiro R.C., Turcq B., Sifeddine A., Lacerda L.D., Silva Filho E.V., Gueiros B., Potty Y.P., Santelli R.E., Pádua E.O., Patchinelam S.R. 2011. Biogeochemical indicators of environmental changes from $50 \mathrm{Ka}$ to $10 \mathrm{Ka}$ in a humid region of the Brazilian Amazon. Palaeogeography, Palaeoclimatology, Palaeoecology, 299:426-436.

Gullison R.E., Frumhoff P.C., Canadell J.G., Field C.B., Neostad D.C., Hayhoe K., Avissar R., Curran L.M., Friedlingstein P., Chris D. 2007. Tropical Forests and Climate Policy. Science, 316. Disponível em: www.sciencemag.org. Acessado em 5 mai 2009.

IBGE - INSTITUTO BRASILEIRO DE GEOGRAFIA E ESTATÍSTICA. 2010. Indicadores de Desenvolvimento Sustentável. Disponível em: http://www.ibge. gov.br/. Acessado em 28 mai 2012.

INMET - INSTITUTO NACIONAL DE METEOROLOGIA. 2009. Normais climatológicas. Disponível em: http://www.inmet.gov.br. Acessado em 26 mai 2012.

Kirby K.R., Laurance W.F., Albernaz A.K., Schroth G., Fearnside P.M., Bergen S., Venticinque E.M., da Costa C. 2006. The future of deforestation in the Brazilian Amazon. Futures, 38:432-453.

Köppen W. 1948. Climatologia: con un estudio de los climas de la tierra. Fondo de Cultura Econômica. México, 479 p.

Meyers P.A. 1997. Organic geochemical proxies of paleoceanographic, palaeolimnologic and paleoclimatic process. Organic geochemistry, 27:213250.

Meyers P.A. 2003. Applications of organic geochemistry to paleolimnological reconstructions: a summary of examples from the Laurentian Great Lakes. Organic geochemistry, 34:261-289.

Meyers P.A. 1994. Preservation of elemental and isotopic source identification of sedimentary organic matter. Chemical Geology, 114:289-302.

Michalski F., Peres C.A., Lake I.R. 2008. Deforestation dynamics in a fragmented region of southern Amazonia: evaluation and future scenarios. Environmental Conservation, 32:93-103.

Pessenda L.C.R., Gouveia S.E.M., Aravena R., Boulet R., Valencia E.P.E. 2004. Holocene fire and vegetation changes in southeastern Brazil as deduced from fóssil charcoal and soil carbon isotopes. Quaternary International, 144:35-43.

RADAMBrasil, Projeto. 1980. Departamento Nacional da Produção Mineral. Levantamento de recursos naturais. Folha SC. 21 Juruena; geologia, geomorfologia, pedologia, vegetação e uso do potencial da terra. Gráfica Alvorada Ltda., Rio de Janeiro, 355 pp.

Whitlock C., Moreno P.I., Bartlein P. 2007. Climatic controls of Holocene fire patterns in southern South America. Quaternary Research, 68:28-36. 